\title{
Small joint involvement: a systematic roentgenographic study in rheumatoid arthritis
}

\author{
JAMES T HALLA ${ }^{*}$ SOHRAB FALLAHI, ${ }^{1}$ AND JOE G HARDIN ${ }^{2}$ \\ From the 'Division of Clinical Immunology and Rheumatology, University of Alabama at Birmingham, \\ University Station, Birmingham, Alabama, USA; and the ${ }^{2}$ University of South Alabama College of Medicine, \\ Mobile, Alabama, USA
}

SUMMARY Standard hand and foot roentgenograms from 200 consecutively hospitalised patients with definite or classical rheumatoid arthritis (RA) were read for marginal erosions by three independent observers. For each joint or group of joints analysed the degree of symmetry ( $S=$ absolute symmetry, $\mathrm{U}=$ unilateral, $\mathrm{PS}=$ partial symmetry) was determined. The total number of joints affected significantly correlated only with disease duration; symmetry of erosions and number of affected patients were not influenced by seropositivity. Metatarsophalangeal erosions (in $70 \%$ ) were the most common and were classified as $\mathrm{S}$ in $16 \%$, $\mathrm{U}$ in $21 \%$, and PS in $63 \%$. Metacarpophalangeal erosions (in $68 \%$ ) were also common, with a symmetry pattern of $\mathrm{S}$ in $19 \%, \mathrm{U}$ in $21 \%$, and PS in $60 \%$. Proximal finger interphalangeal erosions (in $42 \%$ ) were unilateral in $42 \%$ ( $\mathrm{S}$ in $8 \%$ and PS in $50 \%$ ). The only site where symmetry was usual $(90 \%)$ was the wrist, but radiocarpal and intercarpal joints were considered together. Erosions also occurred in about $16 \%$ of the finger distal interphalangeal and $28 \%$ of the great toe interphalangeal joints. In RA roentgenographic asymmetry is usual and unilateral involvement common.

Key words: marginal erosions, joint roentgenography, symmetry.

Marginal erosions are considered to be a characteristic roentgenographic feature of rheumatoid arthritis (RA). ${ }^{-3}$ They have usually been reported to predominate about the metacarpophalangeal (MCP), finger proximal interphalangeal (PIP), intercarpal, wrist, and metatarsophalangeal (MTP) joints. ${ }^{3-5}$ Symmetry of involvement, both roentgenographically and on physical examination, is also considered characteristic of RA. ${ }^{\prime 6}$ Consequently, marginal erosions distributed symmetrically about small hand and foot joints support a diagnosis of RA and help to distinguish it from other inflammatory arthropathies. Because of our observations ${ }^{7}$ suggesting frequent asymmetrical marginal erosions, often occurring about small joints considered uncommonly affected in RA, a systematic study was undertaken to define the distribution and symmetry of small hand and foot joint marginal erosions in patients with established RA.

Accepted for publication 12 September 1985.

Correspondence to Dr Joe G Hardin. University of South Alabama, College of Medicine. 2451 Fillingim Street. Mobile. AL 36617, USA.

*Present address: 1927 Pine Street, Abilene, Texas, USA

\section{Patients and methods}

Two hundred consecutively hospitalised patients with classical or definite RA (American Rheumatism Association criteria) were studied. Their clinical features are summarised in Table 1.

Standard posteroanterior roentgenograms of the hands, wrists, and feet were obtained for all patients, and all films were interpreted by three independent observers. For purposes of this study only marginal erosions read by all three observers about finger distal interphalangeal (DIP), PIP, MCP, first carpometacarpal (CMC), intercarpal, ulnar styloid, wrist (radiocarpal), MTP, and first toe

Table 1 Clinical features of the 200 RA patients studied for small joint erosions

\begin{tabular}{ll}
\hline M/F ratio & $72 / 128$ \\
Mcan age (range) in years & $57(21-83)$ \\
Mcan disease duration (range) in years & $11 \cdot 6(1-50)$ \\
Rheumatoid factor (latex) & $150(75 \%)$ \\
Subcutaneous nodules & $86(43 \%)$ \\
\hline
\end{tabular}


interphalangeal (IP) joints were recorded and analysed. In the wrist area, involvement was characterised as ulnar styloid alone or pancarpal when the ulnar styloid and intercarpal or radiocarpal joints were affected. Erosions were considered marginal when any part of the ulnar styloid was affected or when the erosion occurred adjacent to the joint, just beyond the usual limits of the articular cartilage. Joints with marginal osteophytes were excluded from the analysis. For each joint or group of joints. involvement was considered symmetrical (S) if exactly the same joints on both sides were affected: unilateral (U) if one or more joints on only one side was affected; and partially symmetrical (PS) if both sides were affected, but not necessarily with an identical distribution. Any erosion read by all three observers was sufficient to qualify that joint as affected; no effort was made to quantify the magnitude of erosive changes.

Statistical analyses were performed by the Statistical Analysis System Program.

\section{Results}

Results are summarised in Table 2. Erosions at one or more of the targeted sites were identified in $85 \%$ of the patients. When all joints with roentgenographic features of degenerative joint disease were excluded the DIP was affected in $16 \%$ with the right second and left fifth digits predominating. Erosions occurred about at least one other small hand joint in all but two patients. PIP erosions, present in $42 \%$. tended to predominate in the second and third digits of both hands, and all but one of the patients also had MCP or wrist erosions. The MCPs were the $\overrightarrow{\vec{s}}$ most commonly affected hand joints, with erosions detected in $68 \%$; the second and third digits of both hands predominated. When joints with features of $\frac{\omega}{\omega}$ degenerative disease were excluded the $\mathrm{CMC}$ was $\mathbb{D}$ affected in $10 \%$ of patients, and all but three of these also had PIP or MCP erosions. The wrist area was affected in $64 \%$ of the patients, and involve- $\vec{\circ}$ ment here was more often symmetrical than in the small hand joints. The MTPs were the most commonly affected of all of the joints examined, and ten $(5 \%)$ patients had erosions in this area, with none of ? the other small hand or foot joints affected. Slightly or less than one third of the patients had first toe IP involvement. Absolute symmetry varied widely from one site to another but was uncommon except $\mathrm{o}$ in the wrist. Unilateral involvement was as common as absolute symmetry.

Tests to determine dominance of the right or the left hand were not done, but almost all patients gave a history of right handedness. There were no significant differences between the prevalence of erosions of small hand joints on the two sides. Considering the $U$ distribution: four were right and three were left for the DIP: 19 right and 16 left for the PIP: and 17 right and 10 left for the MCP.

For all joints except the CMC the total number $\stackrel{D}{\Omega}$ affected correlated positively with disease duration $\overrightarrow{0}$ $(p<0 \cdot(0001)$, as did the degree of roentgenographic 3 symmetry $(p<0 \cdot()(0) 1)$. Pancarpal erosions were

Table 2 Small joint erosions in rheumatoid arthritis

\begin{tabular}{|c|c|c|c|c|c|c|c|c|c|}
\hline \multirow[t]{2}{*}{ Joint } & \multirow{2}{*}{$\begin{array}{l}\text { Total number } \\
(\%) \text { of patients } \\
\text { with one or } \\
\text { more erosions }\end{array}$} & \multicolumn{3}{|c|}{ Sirmmetry } & \multirow{2}{*}{$\begin{array}{l}\text { Average number } \\
\text { of involved } \\
\text { joints }\end{array}$} & \multicolumn{3}{|c|}{$\begin{array}{l}\text { l'aticnts with erosions of } \\
\text { this joint and erosions of: }\end{array}$} & \multirow[b]{2}{*}{$M T P$} \\
\hline & & $S$ & $U$ & $P S$ & & $M(P$ & $P / P$ & Pancarpal & \\
\hline DIP* & $\begin{array}{l}32 / 197 \\
(16 \%)\end{array}$ & $22 \%$ & $22 \%$ & $56 \%$ & $3 \cdot 7$ & $\begin{array}{l}29 / 32 \\
(91 \% / 0)\end{array}$ & $\begin{array}{l}29 / 32 \\
(91 \%)\end{array}$ & $\begin{array}{l}23 / 32 \\
(72 \%)\end{array}$ & $\begin{array}{l}26 / 32 \\
(81 \%)\end{array}$ \\
\hline PIP & $\begin{array}{l}82 / 195 \\
(42 \%)\end{array}$ & $s^{\prime \prime \prime}$ & $42 " 0$ & 5()$^{\prime \prime}$ & $3 \cdot 4$ & $\begin{array}{l}76 / 82 \\
(93 \%)\end{array}$ & - & $\begin{array}{l}6+1 / 22 \\
(78 \%)\end{array}$ & $\begin{array}{l}68 / 82 \\
(83 \%)\end{array}$ \\
\hline$M C P^{*}$ & $\begin{array}{l}13(1) / 190) \\
(68 \%)\end{array}$ & $19 \%$ & $21 \%$ & $60 \%$ & 5.1 & - & $\begin{array}{l}77 / 1.30) \\
(59 \%)\end{array}$ & $\begin{array}{l}8.5 / 1.30) \\
(6.5 \%)\end{array}$ & $\begin{array}{l}106 / 13() \\
(82 \%)\end{array}$ \\
\hline $\mathrm{CMC}^{*}$ & $\begin{array}{l}18 / 186 \\
(10 \%)\end{array}$ & $50 \%$ & $5(1 \% \%$ & - & NA $\div$ & $\begin{array}{l}15 / 18 \\
(8.3 \%)\end{array}$ & $\begin{array}{l}9 / 18 \\
(50 \%)\end{array}$ & $\begin{array}{l}9 / 18 \\
(50 \%)\end{array}$ & $\begin{array}{l}14 / 18 \\
(78 \%)\end{array}$ \\
\hline $\begin{array}{l}\text { Ulnar styloid } \\
\text { alone }\end{array}$ & $\begin{array}{l}27 / 199 \\
(14 \%)\end{array}$ & $19 \%$ & $81 \%$ & - & NA & $\begin{array}{l}18 / 27 \\
(67 \%)\end{array}$ & $\begin{array}{l}1(1) / 27 \\
(37 \%)\end{array}$ & - & $\begin{array}{l}22 / 27 \\
(81 \%)\end{array}$ \\
\hline Pancarpal & $\begin{array}{l}99 / 199 \\
(50 \%)\end{array}$ & $y(1 \%$ & $10 \%$ & - & $\mathrm{NA}$ & $\begin{array}{l}89 / 99 \\
(9(1 \%)\end{array}$ & $\begin{array}{l}61 / 99 \\
(62 \%)\end{array}$ & - & $\begin{array}{l}89 / 99 \\
(9(1 \%)\end{array}$ \\
\hline $\mathrm{MTP}^{*}$ & $\begin{array}{l}13.5 / 193 \\
(7(10 \%)\end{array}$ & $16 \%$ & $21 \%$ & $63 \%$ & $4 \cdot 7$ & $\begin{array}{l}109 / 13.5 \\
(81 \%)\end{array}$ & $\begin{array}{l}6.5 / 1.35 \\
(48 \%)\end{array}$ & $\begin{array}{l}8.5 / 135 \\
(6.3 \% / \%)\end{array}$ & - \\
\hline$I P^{*}$ & $\begin{array}{l}55 / 193 \\
(28 \%)\end{array}$ & $55 \%$ & $45 \%$ & - & NA & $\begin{array}{l}42 / 55 \\
(76 \%)\end{array}$ & $\begin{array}{l}36 / 55 \\
(65 \%)\end{array}$ & $\begin{array}{l}36 / 55 \\
(6.5 \%)\end{array}$ & $\begin{array}{l}5(1 / 55 \\
(91 \%)\end{array}$ \\
\hline
\end{tabular}

"DIP=finger distal interphalangeal joint: $P I P=$ finger proximal interphalangeal joint: $\mathrm{MC} P=$ metacarpophalangeal joint: $\left({ }^{\prime} \mathrm{MC}=\mathrm{thumb}\right.$ carpometacarpal joint: $M T P=$ metatarsophalangeal joint: $I P=t o c$ interphalangeal joint

$\div \mathrm{NA}=$ not applicablc. 
Table 3 Influence of seropositivity on roentgenographic symmetry in 200 patients with RA

\begin{tabular}{|c|c|c|c|c|}
\hline Joint & Distribution & $\begin{array}{l}\text { Number }(\%) \text { of rheumatoid } \\
\text { factor positive patients } \\
\text { with erosions }\end{array}$ & $\begin{array}{l}\text { Number }(\%) \text { of rheumatoid } \\
\text { factor negative patients } \\
\text { with erosions }\end{array}$ & Significance \\
\hline PIP & $\begin{array}{l}\text { S } \\
\text { U } \\
\text { PS } \\
\text { Total }\end{array}$ & $\begin{array}{c}8(12 \%) \\
29(44 \%) \\
29(44 \%) \\
66\left({ }^{*} 80 \%\right)\end{array}$ & $\begin{array}{c}3(19 \%) \\
7(44 \%) \\
6(37 \%) \\
16\left({ }^{*} 20 \%\right)\end{array}$ & $\begin{array}{l}\text { NS } \\
\text { NS } \\
\text { NS } \\
-\end{array}$ \\
\hline MCP & $\begin{array}{l}\text { S } \\
\text { U } \\
\text { PS } \\
\text { Total }\end{array}$ & $\begin{array}{l}17(18 \%) \\
19(20 \%) \\
59(62 \%) \\
95\left({ }^{*} 73 \%\right)\end{array}$ & $\begin{array}{c}7(20 \%) \\
9(26 \%) \\
19(54 \%) \\
35\left({ }^{*} 27 \%\right)\end{array}$ & $\begin{array}{l}\text { NS } \\
\text { NS } \\
\text { NS } \\
-\end{array}$ \\
\hline Pancarpal & $\begin{array}{l}\text { S } \\
\text { Total }\end{array}$ & $\begin{array}{c}64(88 \%) \\
9(12 \%) \\
73\left({ }^{*} 74 \%\right)\end{array}$ & $\begin{array}{c}23(88 \%) \\
3(12 \%) \\
26\left({ }^{*} 26 \%\right)\end{array}$ & $\begin{array}{l}\text { NS } \\
\text { NS } \\
-\end{array}$ \\
\hline MTP & $\begin{array}{l}\text { S } \\
\text { U } \\
\text { PS } \\
\text { Total }\end{array}$ & $\begin{array}{c}21(20 \%) \\
23(22 \%) \\
61(58 \%) \\
105\left({ }^{*} 78 \%\right)\end{array}$ & $\begin{array}{c}11(37 \%) \\
5(17 \%) \\
14(46 \%) \\
30\left({ }^{*} 22 \%\right)\end{array}$ & $\begin{array}{l}\text { NS } \\
\text { NS } \\
\text { NS } \\
-\end{array}$ \\
\hline
\end{tabular}

${ }^{*}$ Refers to percentage of all patients with erosions at this joint.

more likely to be found in women $(p=0 \cdot 01)$, and the presence of rheumatoid factor correlated only with first toe IP $(p=0.03)$ and CMC $(p=0.04)$ erosions. There were no other significant correlations between disease features and the number and distribution of the erosions.

The influence of seropositivity on roentgenographic symmetry is summarised in Table 3. Seropositivity did not influence symmetry; in fact complete MTP symmetry was more frequent in the seronegative patients. From Table 3 it is also apparent that seropositivity did not influence the total number of patients affected by erosions at each site. For each site analysed the percentage of affected seropositive patients was approximately the same as the percentage of seropositive patients in the entire study group.

\section{Discussion}

Roentgenographic symmetry in RA may be a matter of definition, but absolute symmetry seems to be the exception rather than the rule. Our data also suggest that unilateral involvement (complete asymmetry) is more common than previously recognised. Consequently, symmetry of erosive changes should not be required for the roentgenographic diagnosis of RA, and complete or partial asymmetry need not exclude that diagnosis. The pancarpal symmetry observed in our study may be an artefact of its design since the radiocarpal and intercarpal joints were analysed together. If individual joints had been considered (as were the MCPs or PIPs) a degree of asymmetry similar to that found for the others might have been observed.
DIP joints may be clinically involved in a significant number of patients with RA, but erosive changes have been observed less frequently. ${ }^{8}$ In our patients, care was taken to exclude any joint with features of degenerative arthritis, and none of our patients had psoriasis. The $16 \%$ frequency of DIP involvement observed in this study may reflect the overall high prevalence of erosive changes in a group of patients with severe and longstanding disease. Like the asymmetrical nature of the erosive changes, this rather prominent DIP involvement is important to recognise, so that it does not lead to diagnostic confusion.

The distribution of other hand-wrist joint marginal erosions in our patients is similar to that reported by other investigators. ${ }^{1459}$ There was no significant right handed predominance of erosive changes in this study. Although synovitis and certain deformities have been reported to predominate in the dominant hand, other observations suggest that this is not necessarily true for roentgenographic changes. ${ }^{4}$ MTP erosions have been commonly observed, though generally they have not been as prominent as in our patients. ${ }^{13} 59-11$

Great toe involvement in RA has received little attention, but the frequency and distribution of the involvement noted in this study are similar to those reported by Resnick, who observed roentgenographic abnormalities of this joint in 32 of 50 patients, with bilateral changes in $18 .{ }^{12}$

Most reports addressing the issue have correlated roentgenographic erosive changes with rheumatoid disease duration and severity. ${ }^{13}{ }^{14}$ It is not clear why subcutaneous nodules did not correlate better with the severity (number) of marginal erosions in our 
patient population; however, the disease was unusually severe and long standing, resulting in an unusually high prevalence of marginal erosions. If more patients with early or mild disease had been included in this series stronger clinicalroentgenographic correlations might have been made.

Erosions and global symmetry were strongly correlated with seropositivity in a blinded roentgenographic study by Burns and Calin. ${ }^{15}$ and it is not clear why the results of our study differ from theirs. In the present study the patient population was larger but there were still relatively few seronegative patients. The patients studied by Burns and Calin were persistently seronegative, while ours may not have been; most were studied at only one point in time. In the present study the major focus was on symmetry and not on the overall degree of destruction. If the severity of erosions (and other destructive changes) had been quantified a better correlation between seropositivity and roentgenographic changes might have been observed.

Marginal erosions are extremely common roentgenographic manifestations of established RA and they predominate about the MCP. PIP, wrist, and MTP joints; however, DIP and great toe IP erosions occur frequently and do not argue against a diagnosis of RA. Marginal erosions adjacent to hand, wrist, and feet joints are often unilateral and are uncommonly perfectly symmetrical. Roentgenographic asymmetry in RA need not cause diagnostic confusion.

\section{References}

1 Resnick D, Niwayama G. Rheumatoid arthritis and the seronegative spondyloarthropathies: radiographic and pathologic concepts. In: Resnick D. Niwayama G, eds. Diagnosis of bone and joint disorders. Philadelphia: Saunders, 1981: 8501007.

2 Bywaters E. The early radiological signs of rheumatoid arthri-O tis. Bull Rheum Dis 1960: 11: 231-4.

3 Martel W. Radiologic manifestations of rheumatoid arthritis with particular reference to the hand. wrist and foot. Med Clin North Am 1968: 52: 655-65.

4 Martel W. Hayes J. Duff I. The pattern of bone erosion in the hand and wrist in rheumatoid arthritis. Radiology 1965: 84: 204-14.

5 Brook A. Corbett M. Radiographic changes in early rheumatoid disease. Ann Rheum Dis 1977: 36: 71-3.

6 Harris E D Jr. Rheumatoid arthritis: the clinical spectrum. In: Kelley W N. Harris E D Jr. Ruddy S. Sledge C B, eds. Textbook@ of rheumatology. 2nd ed. Philadelphia: Saunders, 1985: 915-55.

7 Halla J T, Fallahi S. Hardin J G. Rheumatoid small joint $\frac{\vec{c}}{\mathrm{C}}$ involvement is not radiographically symmetrical. Arthritis Rheum 1983: 26: S54.

8 McCarty D J Jr. Gatter R A. A study of distal interphalangeal N joint tenderness in rheumatoid arthritis. Arthritis Rheum 1966: 9: $325-36$.

9 Thould A K. Simon G. Assessment of radiological changes in the hands and feet in rheumatoid arthritis. Ann Rheum Dis 1966: 25: 220-8.

10 Berens D. Lockie L. Lin R. Norcross B M. Roentgenographic changes in early rheumatoid arthritis: wrists-hands-feet. Radiol- $\vec{c}$ ogy 1964: 82: $645-54$.

11 Martel W. Acute and chronic arthritis of the foot. Semin Roentgenol 1970): 5: 391-406.

12 Resnick D. The interphalangeal joint of the great toe in rheumatoid arthritis. J Can Assoc Radiol 1975: 26: 255-62.

13 Sharp J. Radiographic evaluation of the course of articular disease. Clin Rheum Dis 1983: 9: 541-57.

14 Sharp J. Lidsky M. Duffy J. Clinical responses during gold therapy for rheumatoid arthritis: changes in synovitis, radiologically detectable erosive lesions. serum proteins and serologic응 abnormalities. Arthritis Rheum 1982: 25: 540-9.

15 Burns $\mathrm{T}$ M. Calin $\mathrm{A}$. The hand radiograph as a diagnostic discriminant between seropositive and seronegative rheuma-O toid arthritis": a controlled study. Ann Rheum Dis 1983; 42: $605-12$ 